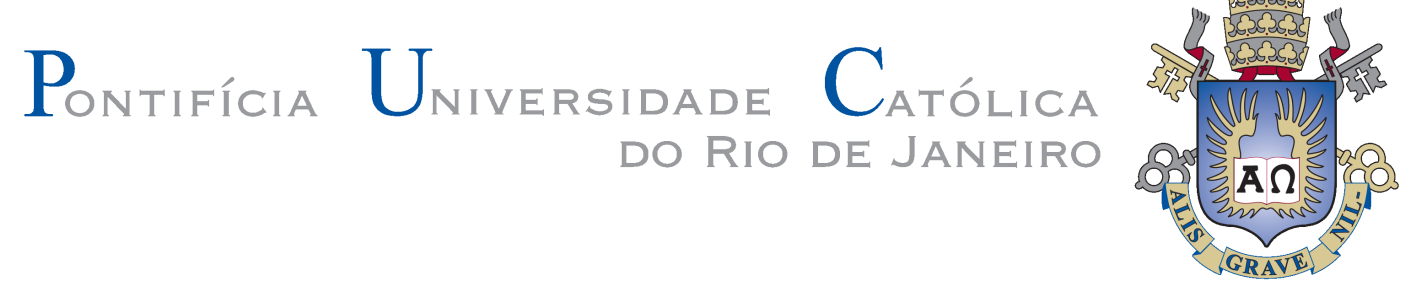

Cristiana de Almeida Fernandes

\title{
O Mito Em Chico Bento e Papa-Capim
}

\author{
Dissertação de Mestrado
}

Dissertação de mestrado apresentada ao Programa de Pós-Graduação em Design da PUC-Rio como requisito parcial para obtenção do título de mestre em Design.

Orientador: Profa. Dra. Vera Lucia dos Santos Nojima

Rio de Janeiro

Junho de 2006 


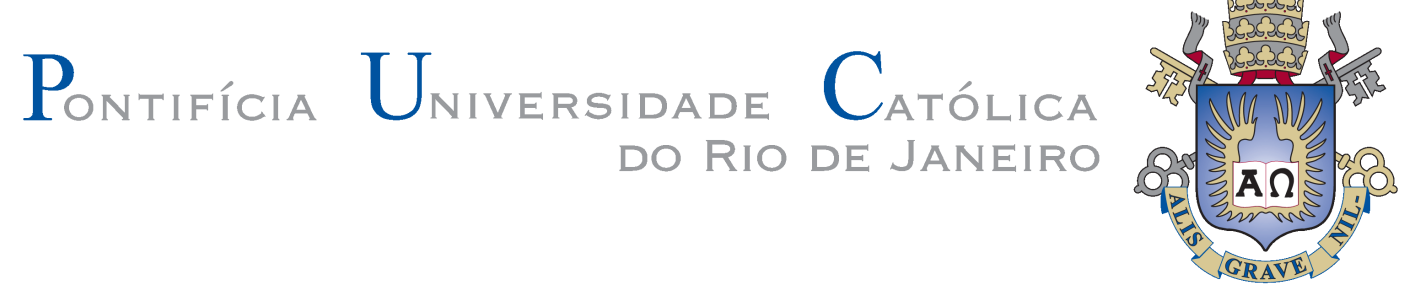

Cristiana de Almeida Fernandes

\section{O Mito Em Chico Bento e Papa-Capim}

Dissertação de mestrado apresentada ao Programa de Pós-Graduação em Design da PUC-Rio como requisito parcial para obtenção do título de mestre em Design.

Profa. Dra. Vera Lucia dos Santos Nojima

Orientador

Departamento de Artes \& Design - PUC-Rio

Profa. Dra. Angeluccia Bernardes Habert Departamento de Comunicação Social - PUC-Rio

Prof. Dr. Nilton Gonçalves Gamba Junior Fundação Getúlio Vargas - São Paulo

Prof. Dr. Paulo Fernando Carneiro de Andrade

Coordenador Setorial do Centro de Teologia e Ciências Humanas - PUC-Rio

Rio de Janeiro, 30 de Junho de 2006 
Todos os direitos reservados. É proibida a reprodução total ou parcial do trabalho sem autorização da universidade, do autor e do orientador.

\section{Cristiana Fernandes}

Graduou-se em Design em dezembro de 1996 pelas Faculdades Integradas Teresa D'Avila - Lorena, SP. Pós-graduada em Comunicação e Imagem, pela Pontifícia Universidade Católica do Rio de Janeiro. Também pós-graduada em Advanced School of Internet Technology, pelo IBPI-NET/COPPE - UFRJ. Dedicase atualmente à carreira de professora universitária em Comunicação Social e Design, além de atuar como designer em projetos free lancer.

Ficha Catalográfica

Fernandes, Cristiana de Almeida

O mito em Chico Bento e Papa-Capim / Cristiana Fernandes ; orientadora: Vera Lúcia Moreira dos Santos Nojima. - Rio de Janeiro : PUC-Rio, Departamento de Artes \& Design, 2006.

165 f. : il. ; $30 \mathrm{~cm}$

Dissertação (mestrado) - Pontifícia Universidade Católica do Rio de Janeiro, Departamento de Artes \& Design .

Inclui bibliografia.

1. Artes - Teses. 2. Quadrinhos. 3. Mito. 4. Semiologia. 5. Mauricio de Sousa. 6. Imaginário. 7. Design. 8. Ficção. Não-ficção. I. Nojima, Vera Lúcia Moreira dos Santos. II. Pontifícia Universidade Católica do Rio de Janeiro. Departamento de Artes \& Design. III. Título.

CDD: 700 
Ao meu porto-seguro, coadjuvantes no meu sonho e produtores de sonhos que se antecederam aos meus:

Minha mãe Uyara, que me deixou o legado da sala de aula, que amava o magistério como a Dona Marocas.

Meu pai Vicente (Don Vincent de las Mulas Mancas), o melhor pescador, contador de "causos", dotado da melhor saúde e engraçado como o Chico Bento. À Rosinha sonhadora, formosa, competente e insistente em suas causas, que vive na roça, como pajé aos Papa-Capins e Cafunés do nosso Brasil, minha irmã Daniella.

À minha Dona Marocas, incentivadora dos meus projetos de vida. Levo minha maçã às notas 10 que me deu, Ana Paula Zarur.

Ao companheirismo de Lélia Campos.

À amizade sempre de Silvio Machado. 


\section{Agradecimentos}

Agradeço ao ombro de Daniel Pinna e às palavras de Luiz Carlos, companheiros de PUC.

À minha orientadora Vera Nojima, que sabe escutar e possui a qualidade do "nível do chão" junto aos seus orientandos, sendo compreensiva e dura na hora certa.

Ao Moacy Cirne, pela sua bibliografia sobre quadrinhos tão exemplar, tipicamente brasileira, referência a qualquer estudioso sobre essa forma de linguagem.

Aquele que segurou a barra no trabalho com a maior paciência. Um grande agenciador de empregos e exímio organizador de tarefas, Andrei Scheiner.

À Diretora da Escola de Comunicação e Artes do Centro Universitário da Cidade, que encara as maçãs oferecidas aos professores como suborno (mas eu encaro como agradinho), Ana Mascia Lagôa.

À Diretora das Faculdades Integradas Teresa D'Ávila e excelente semioticista, D. Sc. Olga de Sá: "Semiótica é coisa muito séria."

À Luciana Sarmento que aceitou a empreitada de revisar, em cima da hora, essa dissertação. 
Aos membros da banca, D. Sc. Angeluccia Bernardes Habert (Depto. de Comunicação PUC) e D. Sc. Nilton Gonçalves Gamba Junior. Mil perdões pela falta de tempo para lerem esse trabalho.

À Carina e às demais bibliotecárias das Faculdades Integradas Teresa D’Ávila, pelo esforço na busca de bibliografia de apoio ao curso das disciplinas obrigatórias do Mestrado.

À aluna e amiga e orientanda Viviane Gomes, que após capturar as imagens presentes em 24 revistas se tornou tão entendida da composição dos quadrinhos de Mauricio de Sousa, que desistiu do tema de monografia de conclusão do curso de Publicidade e Propaganda em cima da hora, para entender a influência da imagem de Mauricio de Sousa nas embalagens dos produtos.

Ao amigo Luiz Antonio Coelho: “devemos enxergar primeiro o chão, depois o muro à nossa frente" - palavras no momento de desespero. Quando eu falava do mito, ele me apresentou Roland Barthes; quando eu falava em seqüência, ele me apresentou a narrativa; quando eu falava de elementos, ele me falou de sintaxe.

À amiga Denise Portinari, que me ouviu e me apresentou o "sujeito"; que leu e me apresentou o "imaginário".

Ao Raphael Mohamed, Flávia Mauricio e Laerte Ferreira, pela intermediação aos contatos com Mauricio de Sousa, essenciais para a pesquisa.

À Andrea Goeb.

Ao Mestre Mauricio de Sousa. 


\section{Resumo}

Fernandes, Cristiana de Almeida; Nojima, Vera Lucia dos Santos. O Mito em Chico Bento e Papa-Capim. Rio de Janeiro, 2006. 165p. Dissertação de Mestrado - Departamento de Artes \& Design, Pontifícia Universidade Católica do Rio de Janeiro.

O presente trabalho analisa as histórias em quadrinhos de Mauricio de Sousa sob a ótica da Semiologia, avaliando o uso do Mito para a transmissão de um conteúdo ideológico. Para essa análise, foi necessário situar os quadrinhos no âmbito do Design Gráfico e entender que a construção da mensagem utiliza-se não só da imagem, mas também do texto, como elementos de construção de significado. Pôde-se perceber que as figuras ditas mitológicas, presentes na obra de Mauricio de Sousa - especificamente nos quadrinhos da Turma do Chico Bento e da Turma do Papa-Capim publicados nos anos de 2004 e 2005 -, transitam pelos quadros contracenando com as demais personagens. Fazem parte do conteúdo não em ambientes metafísicos, mas tomando o lugar do humano, como qualquer outra personagem nos espaços narrativos das histórias que são referendos do real. Assim, os ambientes ou lugares narrativos das histórias de Mauricio de Sousa permitem que animais, objetos, figuras folclóricas e até plantas sejam representados como humanos, com características antropomórficas, dotados de razão e personalidade, sendo assimilados desta forma pelo imaginário do interlocutor.A pesquisa procurou levantar as imagens presentes nos temas tratados e, assim, pelo viés do design gráfico, vem trazendo algumas questões semiológicas na abordagem a respeito do Mito - baseando-se, principalmente, nos conceitos de Barthes sobre o assunto - usando o conteúdo imagético da obra de Mauricio de Sousa..

\section{Palavras-chave}

Quadrinhos; Mito; Semiologia; Mauricio de Sousa; Imaginário; Design; Ficção; Não-ficção. 


\section{Abstract}

Fernandes, Cristiana de Almeida; Nojima, Vera Lucia dos Santos. The Myth in Chico Bento and Papa-Capim. Rio de Janeiro, 2006. 165p. MSc. Dissertation - Departamento de Artes \& Design, Pontifícia Universidade Católica do Rio de Janeiro.

This research analyses Mauricio de Sousa's cartoons under the semiotics' view by analysing the myth as a communication tool of some ideology content. In order to carry on this analysis, it was necessary place the cartoons into the graphic design scope and understand the construction of the message uses not only image, but also text as building elements of the significance. By studying the so-called mythological characters from Mauricio de Sousa's work - specially the cartoons from Chico Bento's and Papa-Capim's Gangs published in 2004 and 2005 -, the study realised that its flows through the cartoons by playing with others characters, in the same content, not just in metaphysic environment but taken place the human, like any other, into the narrative places that are the reference of the real. Therefore we can say that the environment or the Mauricio de Sousa's cartoons narrative places, allow animals, objects, folkloric characters and even plants being represented like humans with anthropomorphic characteristic endowed with reason and personality being assimilated by the interlocutor imagination. This analysis, the research tried to discuss the images on the themes through the graphic design view point, bring together some questions on semiology about the myth - based upon, specially, Barthes' concepts about the subject - by using the imaginary contents from Mauricio de Sousa's work.

\section{Key-words}

Cartoons; Myth; Semiotics; Mauricio de Sousa; Imaginary; Design; Fiction; Non-Fiction. 


\section{Sumário}

1 Conhecendo o objeto de pesquisa

18

2 Um olhar para a obra de Mauricio de Sousa:

Mito / Ideologia / Narrativa / Unidades de Construção

30

3 Conhecendo os componentes da construção da obra 39

3.1. As personagens

3.1.1 Apresentação das personagens que fazem parte da Turma do Chico Bento 40

3.1.2 Apresentação das personagens que fazem parte da Turma do Papa-Capim

3.2 Unidades de construção de sentido descritas por Will Eisner, aplicadas a Mauricio de Sousa

3.2.1 Turma do Chico Bento

Ficha técnica das personagens

3.2.2 Turma do Papa-Capim

Ficha técnica das personagens

4 A construção do mito mauriciano

4.1 Construção do Rroteiro

4.2 Desenho

5 Eu acredito em Mauricio de Sousa 


\section{Lista de figuras}

Figura 1 - A Turma da Mônica já é conhecida

internacionalmente

Figura 2 - A Turma da Mônica em campanha de

segurança no trânsito 26

Figura 3 - A Turma da Mônica em outros países 26

Figura 4 - Exemplar da revista Gibi 28

Figura 5 - A Turma da Mônica em um canal de televisão infantil

Figura 6 - Anúncio publicado na revista Chico Bento em março de 2006.

Figura 7 - Imagem captada do site <www.monica.com.br> em abril de 2006

Figura 8 - Chico Bento $\quad 40$

Figura 9 - Dona Marocas $\quad 40$

Figura 10 - Giselda $\quad 41$

Figura 11- Hiro $\quad 41$

Figura 12 - Mãe do Chico Bento $\quad 41$

Figura 13 - Nhô Lau 42

Figura 14 - Padre Lino 42

Figura 15 - Pai do Chico Bento 42

Figura 16 - Primo Zeca 43

Figura 17 - Rosinha $\quad 43$

Figura 18 - Torresmo $\quad 43$

Figura 19 - Vó Dita $\quad 44$

Figura 20 - Zé da Roça $\quad 44$

Figura 21 - Zé Lelé $\quad 44$

Figura 22 - Cacique Ubiraci $\quad 45$

Figura 23 - Cafuné $\quad 45$

Figura 24 - Jurema $\quad 45$

Figura 25 - Pajé $\quad 46$

Figura 26 - Papa-Capim $\quad 46$ 
Figura 27 - Exemplos de anatomia expressiva corporal 54

Figura 28 - Rosto assustado 55

Figura 29 - Rosto alegre/satisfeito ou amedrontado $\quad 55$

Figura 30 - Rosto argumentando ou apaixonado $\quad 56$

Figura 31 - Rosto beijando, confuso, dormindo

desacordado, tonto, em transe ou desconfiado $\quad 56$

Figura 32 - Rosto empolgado, encabulado, encurralado

ou guloso 57

Figura 33 - Rosto ignorando, impaciente ou inibido 58

Figura 34 - Rosto indeciso ou orgulhoso 58

Figura 35 - Rosto pensativo, questionando ou nervoso $\quad 59$

Figura 36 - Sinais gráficos $1 \quad 60$

Figura 37 - Sinais gráficos $2 \quad 61$

Figura 38 - Sinais gráficos $3 \quad 61$

Figura 39 - Sinais gráficos $4 \quad 62$

Figura 40 - Sinais gráficos $5 \quad 62$

Figura 41 - Sinais gráficos $6 \quad 63$

Figura 42 - Exemplos de anatomia expressiva na obra de Mauricio de Sousa 63

Figura 43 - Cafuné e Papa-Capim $\quad 64$

Figura 44 - Papa-Capim pulando $\quad 64$

Figura 45 - Raiva, alegria e medo $\quad 66$

Figura 46 - Chico Bento e as galinhas 68

Figura 47 - Chico Bento e os fantasmas $\quad 69$

Figura 48 - Chico Bento e o lobisomem $\quad 70$

Figura 49 - Papa-Capim acha a flecha 72

Figura 50 - Papa-Capim luta com a flecha $\quad 72$

Figura 51 - Chico Bento e as mentiras $\quad 73$

Figura 52 - Rosinha e as flores $\quad 74$

Figura 53 - Balão metalingüístico $\quad 74$

Figura 54 - Chico Bento aprende a nadar $\quad 75$

Figura 55 - Chico Bento caindo $\quad 75$

Figura 56 - Chico Bento grita $\quad 76$ 
$\begin{array}{ll}\text { Figura } 57 \text { - Batidas na porta } & 76\end{array}$

Figura 58 - Onomatopéia - porta batendo $\quad 76$

Figura 59 - Outra porta batendo $\quad 77$

Figura 60 - Pancada $1 \quad 77$

Figura 61 - Pancada $2 \quad 77$

Figura 62 - Onomatopéia de trovão $\quad 78$

Figura 63 - Onomatopéia de briga 78

Figura 64 - Onomatopéia de quebra $\quad 78$

Figura 65 - Onomatopéia de corneta $\quad 79$

Figura 66 - Onomatopéia de mergulho $\quad 79$

Figura 67 - Tchof $\quad 79$

Figura 68 - Arquitetura da oca em Papa-Capim $\quad 80$

Figura 69 - Exemplos de cenário em Papa-Capim $\quad 80$

Figura 70 - Mais exemplos de cenário em Papa-Capim 80

Figura 71 - A natureza retratada em Papa-Capim $\quad 81$

Figura 72 - Exemplos de arquitetura em Chico Bento 81

Figura 73 - Mais um exemplo de arquitetura em Chico Bento 81

Figura 74 - Exemplos de natureza em Chico Bento 82

Figura 75 - Mais exemplos de natureza em Chico Bento 82

Figura 76 - A natureza ainda retratada em Chico Bento 82

Figura 77 - Mais exemplos de natureza retratada

em Chico Bento 82

Figura 78 - Balão mágico - construção de fala para seres mágicos

Figura 79 - Balão desorganizado - geralmente quando

a fala produz interferência de sons ou gritos

Figura 80 - Balão de pensamento; construção

da imagem pelo olhar ou pensamento da própria personagem

Figura 81 - Balão de pensamento múltiplo - mostra que dois ou mais personagens estão pensando a mesma coisa

Figura 82 - Balão uníssono; a mesma fala emitida por personagens diferentes

Figura 83 - Balão de cochicho ou sussurro, 
usado com as bordas tracejadas

Figura 84 - Narração épica. O enquadramento imita uma

folha de papel. Como se a história estivesse sendo

contada através de uma carta ou bilhete.

86

Figura 85 - Narração tradicional. Pode ser usado como passagem

do tempo ou simplesmente introduzindo uma história 86

Figura 86 - Texto visto através da imagem dentro de balões $\quad 87$

Figura 87 - Pensamento $\quad 87$

Figura 88 - Novamente, a imagem nos balões $\quad 87$

Figura 89 - Uma história contada com onomatopéia 88

Figura 90 - Uma história contada sem onomatopéia 88

Figura 91 - Fonte usada por Mauricio de Sousa

em seus quadrinhos $\quad 89$

Figura 92 - Distância entre o texto e a borda dos balões $\quad 90$

Figura 93 - Exemplo de fonte em Chico Bento 90

Figura 94 - Outro exemplo de fonte em Chico Bento 90

$\begin{array}{ll}\text { Figura } 95 \text { - Placa } & 91\end{array}$

Figura 96 - Sinais gráficos acompanham a fonte

em Chico Bento $\quad 91$

Figura 97 - A cor rosa foi usada juntamente com

um coração no lugar do "O" $\quad 91$

Figura 98 - Fonte cursiva para acompanhar a forma $\quad 91$

Figura 99 - Sinais gráficos acompanham o texto.

A palavra "Mãe" foi valorizada $\quad 91$

Figura 100 - Fundos em dégradé em Chico Bento 92

Figura 101 - Esquema de simplificação $\quad 97$

Figura 102 - Esquema mitológico e o significante 98

Figura 103 - Imagem extraída do livro de Guto Lins (2002)

sobre o livro infantil 99

Figura 104 - Chico Bento e o Saci 100

Figura 105 - Chico Bento e Rosinha 101

Figura 106 - A cortesia caipira 103

Figura 107 - "Mauricio Bento" 104 
Figura 108 - As histórias de Vó Dita 110

Figura 109 - As características indígenas em Papa-Capim 112

Figura 110 - Papa-Capim em contato com outras culturas 112

Figura 111 - Vida boa do Chico Bento 113

Figura 112 - Espaço amplo nos quadrinhos de Chico Bento 113

Figura 113 - Exemplo de como a mãe de Chico Bento

atua nas histórias $\quad 114$

Figura 114 - Descrição de Chico Bento 116

Figura 115 - Exemplo de como os animais atuam

em Chico Bento

Figura 116 - Outro exemplo da atuação de animais

em Chico Bento

Figura 117 - Os animais e o padre em Chico Bento:

valorização da moral

Figura 118 - Imagem retirada do livro comemorativo

dos 40 anos da Mônica (SOUSA, 2005b) 119

Figura 119 - Exemplo do ambiente rural em Chico Bento 120

Figura 120 - Outro exemplo do ambiente rural

em Chico Bento

Figura 121 - Amplitude ao plano nos quadrinhos

de Mauricio de Sousa

122

Figura 122 - Indicação de altura no plano nos quadrinhos

de Mauricio de Sousa

122

Figura 123 - Exagero de sensação nos quadrinhos

de Mauricio de Sousa

122

Figura 124 - A evolução da personagem Chico Bento 124

Figura 125 - Personagens com necessidades

especiais: atualidade

126

Figura 126 - Características de situações nos

quadrinhos de Mauricio de Sousa

127

Figura 127 - Outro tipo de ambientação nos quadrinhos

de Mauricio de Sousa

128

Figura 128 - Conteúdo histórico e ecológico

128 
Figura 129 - Iracema

Figura 130 - Chico Bento contracena com personagens

do folclore

131

Figura 131 - Bode - gestual de surpresa 132

Figura 132 - Bode - sinais de raiva 132

Figura 133 - Bode - casaco e expressão de felicidade 132

Figura 134 - Bode - tremendo de frio 133

Figura 135 - Burro - em situação metalingüística,

querendo aparecer, com sorriso e

posicionamento de autoridade

133

Figura 136 - Burro - surpreso 134

Figura 137 - Cachorro - satisfeito 134

Figura 138 - Cachorro - Formato de boca

(biquinho) humano, atribuindo gesto humano de beijo 134

Figura 139 - Cachorro - gargalhando

Figura 140 - Cachorro - movimentos exagerados

Patas traseiras viram pés. Patas dianteiras viram mãos. Expressão de aflição.

Figura 141 - Cachorro - sorriso sem graça

("sorriso amarelo")

Figura 142 - Cachorro - intenção de reação

Pata dianteira vira mão.

Figura 143 - Cachorro - responde a uma pergunta, expressando uma negativa

Figura 144 - Carneiros - trabalhando

Figura 145 - Rosto?

Figura 146 - Rosinha - figurinos diferentes,

mesma expressão

Figura 147 - Chico Bento se arruma

Figura 148 - Imagem de um anjo barroco detalhado em ouro da Catedral Metropolitana de Diamantina, MG

Figura 149 - Seres mágicos em Papa-Capim

Figura 150 - Papa-Capim no campo de Chico Bento 
Figura 151 - Zé Lelé e a Mula Sem Cabeça

Figura 152 - Papa-Capim e a cobra 


\section{Lista de tabelas}

Tabela 1 - Aspectos formais da Turma do Chico Bento

Tabela 2 - Aspectos sociais e de personalidade da Turma do Chico Bento 47

Tabela 3 - Aspectos formais da Turma do Papa-Capim 50

Tabela 4 - Aspectos sociais e de personalidade

da Turma do Papa-Capim 